\title{
Numerical Assessment of Factors Affecting Waveform Based on Low Strain Testing of Piles
}

\author{
Zegen Wang*, Yifeng Wu and Zuocheng Xiao
}

School of Civil Engineering and Architecture, Southwest Petroleum University, Chengdu 610500, China

\begin{abstract}
In this paper dynamic testing of piles using the low strain method is performed by means of numerical analyses based on solid finite element model. To this end, velocity-time curves are presented investigating the influence of various parameters such as mesh density, impulse width, receiving point, and soil modulus on the waveform characteristics. Then, find regularity of waveform affected by different parameters to provide reference of the real project detection.
\end{abstract}

Key words: Dynamic testing of piles, finite element, low strain method, velocity versus time curve, waveform.

\section{INTRODUCTION}

As one of the most applied dynamic testing of piles, the low strain method is widely used in pile integrity detection. The theory of low strain method is measuring velocity versus time curve with low transient energy or steady-state vibration at the top of the pile, through the wave theory analysis or frequency domain analysis to decision the pile's integrity.

Usually, the form of velocity versus time curve resulted from low strain method is so complex because of masses of interference factors which cause people cannot totally understand its regularity so that only simple type of defect identification can be done based on field testing. Therefore, it is necessary to pay more attention on study of regularity of low strain waveform. Influences of dimension effect on low strain testing of pile have been studied [1, 2]. Chow researched the three-dimensional effect of axisymmetric pile based on low strain method [3]. Huang, et al. explore reflection pulse signal characteristics measured from different receiving points at the pile top and the laws correspondence with the pile cracks [4]. Difference method has been used for low strain pile detection by Liu and his colleagues, the effect is proven very well because of smaller mesh and higher accuracy [5-8]. Zhang, et al. analyzed factors resulted from impact hammer affecting dynamic testing of piles [9]. Chen studied the waveform of reflection pulse of defect pile in real engineering based on low strain [10]. Ding did some research on the low strain reflection pulse of pipe pile $[11,12]$. Wang researched various kinds of necking piles through numerical assessment to simulate necking defects with different extents, locations, lengths, etc. [13]. This paper, a pile-soil model (the pile is integral with not any defect which is hard to realize in real project) has been established to simulate law strain detection with software ABAQUS/Expilcit, through changing the parameters of pile respectively

*Address correspondence to this author at the School of Civil Engineering and Architecture, Southwest Petroleum University, Chengdu 610500, China; Tel: 86-2883037628; Fax: 86-2883037601; E-mail: zegen01@126.com including mesh density, impulse width, receiving point and modulus of soil to achieve and analyze kinds of velocity versus time curves. Then, find regularity of waveform affected by different parameters to provide reference of the real project detection.

\section{FINITE ELEMENT MODELING}

Tanchanis's research manifest that the model size with longitudinal length of 1.7 times of pile length and radial length of 24 times of diameter is large enough to the single pile analysis [14]. Randolph thought the longitudinal length should be 2.5 times of pile length and the radial length should be 50 times of diameter [15]. The London clay test conducted by $\mathrm{COOK}$ indicates that the shear displacement can be omitted when soil diameter is 10 times of pile diameter and the soil diameter usually is 5-6 times of pile diameter in practical engineering [16]. Therefore, based on ABAQUS/Explicit, a $16 \mathrm{~m}$ uniform integral pile model with $1 \mathrm{~m}$ diameter was built. The soil's diameter is set as 10 times of pile and the depth below the pile is set to $8 \mathrm{~m}$. The pile was regard as a liner elastic material and the same assumption also did on the soil. Here, both the pile and soil adopted 8-node finite element C3D8R to mesh [17]. The model is shown respectively in Figs. (1-3) shows the combination model.

\section{THE DETERMINATION OF MESH SIZE}

In order to make the waveform of velocity versus time curve presented in the figure more obvious, an appropriate mesh size has to be determined before doing the following tests. In this part, different mesh size has been determined to observe which one is suitable. Table $\mathbf{1}$ shows the material parameters of the pile-soil model. The peak of impact force is set to $6 \mathrm{~N}$ and impulse width is $2 \mathrm{~ms}$. Setting the mesh size respectively to $300 \mathrm{~mm}, 200 \mathrm{~mm}, 100 \mathrm{~mm}$ and $50 \mathrm{~mm}$ to acquire the following velocity versus time curves are presented in Fig. (4). 


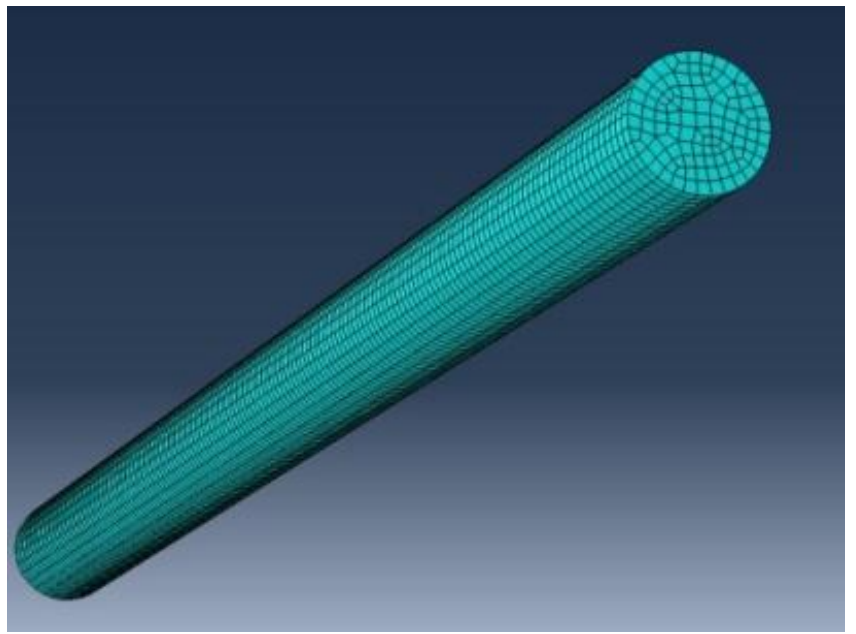

Fig. (1). Model of pile.

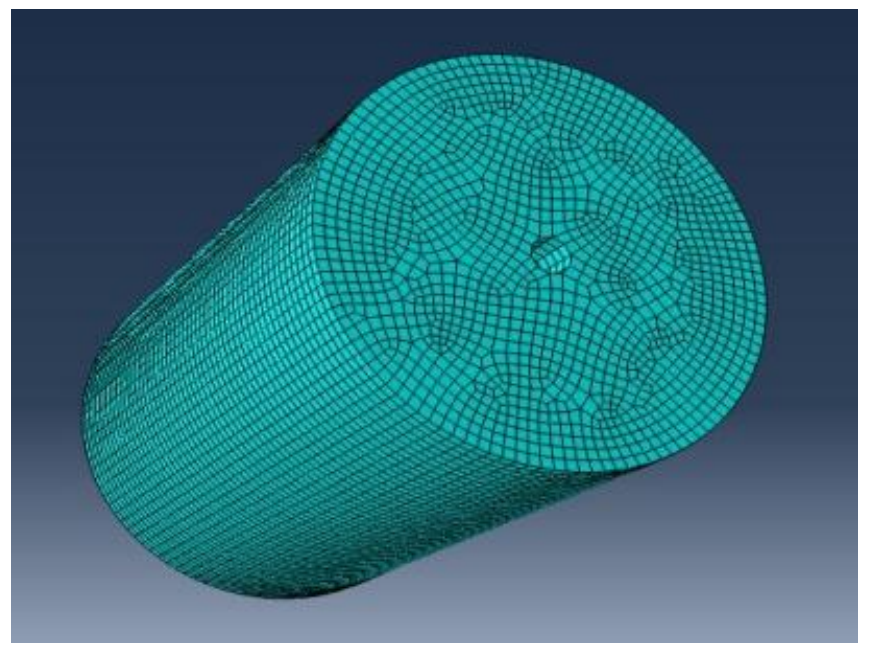

Fig. (2). Model of soil.

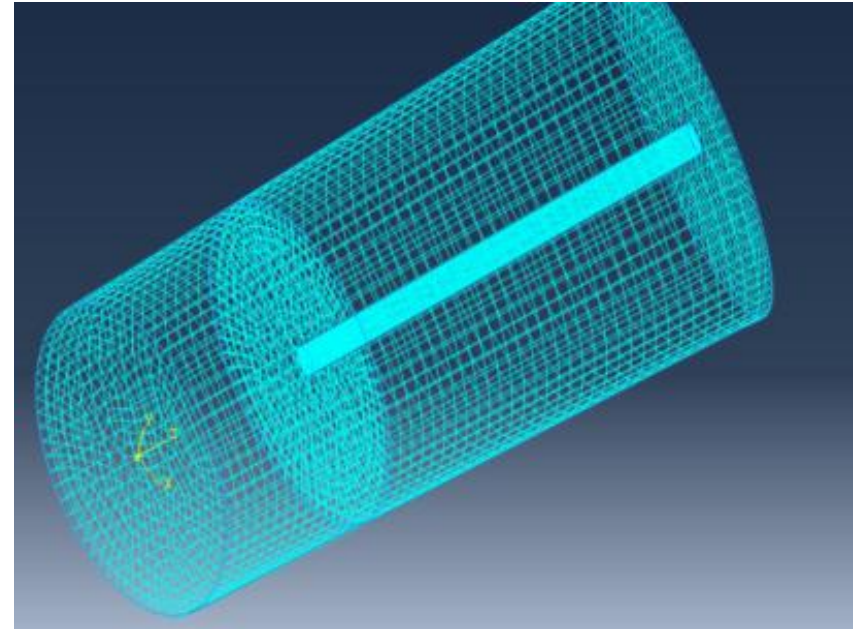

Fig. (3). Model of pile-soil.

Comparison of curves, with the refinement of mesh size division of the model, the main characters of velocity versus time curve is tending to stability. However, when the mesh is set $50 \mathrm{~mm}$ the reflection pulse from pile toe attenuate that is not good for observation. So the mesh size is set as $100 \mathrm{~mm}$ is appropriate.

\section{INFLUENCE OF WAVEFORM DUE TO PULSE WIDTH}

As we all known that different materials of the impact hammer result in different impulse width. With the hammer's stiffness increases gradually from wood to nylon to iron, the generated impulse width narrows gradually. Therefore, in this part, influence of waveform due to pulse width has been researched. The width is set respectively to $0.5 \mathrm{~ms}, 1.0 \mathrm{~ms}$,

Table 1. Material parameters of pile-soil model.

\begin{tabular}{|c|c|c|}
\hline & Density & Modulus \\
\hline \hline Pile & $2500 \mathrm{~kg} / \mathrm{m}^{3}$ & $3 \times 10^{10} \mathrm{~Pa}$ \\
\hline Soil around pile & $1900 \mathrm{~kg} / \mathrm{m}^{3}$ & $1 \times 10^{7} \mathrm{~Pa}$ \\
\hline Soil below pile & $2500 \mathrm{~kg} / \mathrm{m}^{3}$ & $3 \times 10^{9} \mathrm{~Pa}$ \\
\hline
\end{tabular}

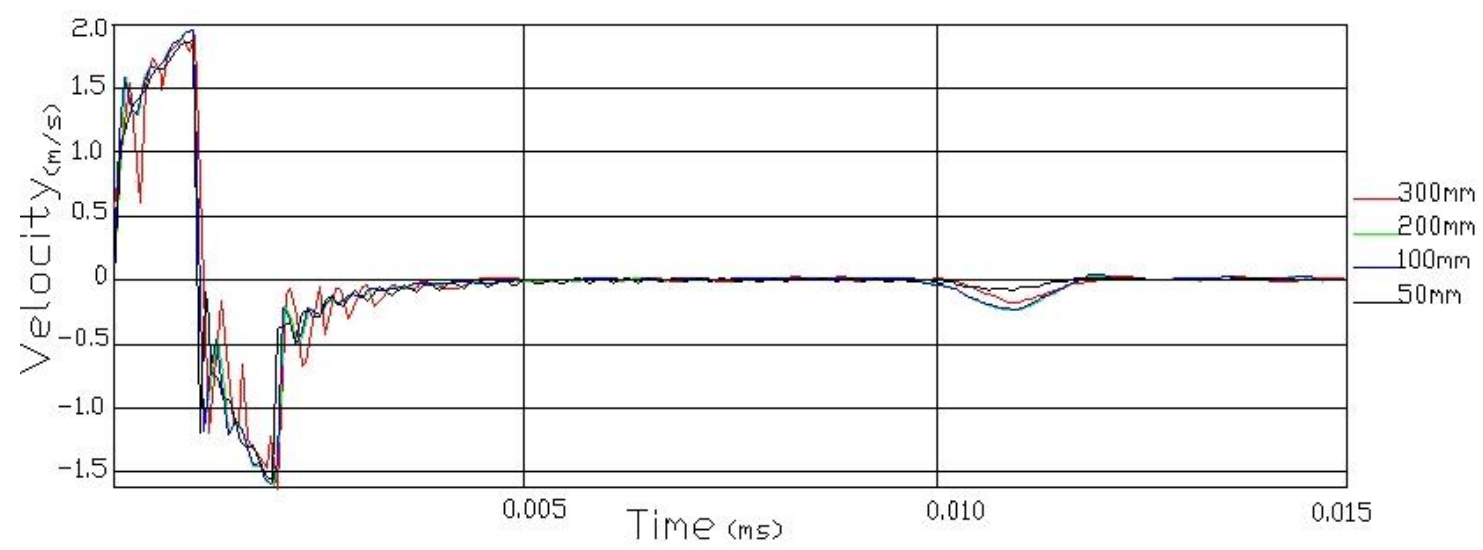

Fig. (4). Velocity versus time curve with different mesh size. 
$1.2 \mathrm{~ms}, 1.5 \mathrm{~ms}$ and $2.0 \mathrm{~ms}$, and the other parameters remain the same, then acquire 5 curves are shown in Fig. (5). The Table 2 records the waveform parameters under these five situations.

Fig. (5) and Table 2 show that it's hard to observe the reflection from the pile toe when the pulse width is as $0.5 \mathrm{~mm}$. This phenomenon is due to fluctuation interference. With pulse width gradually increases to $2 \mathrm{~ms}$, reflection from the pile toe presents more and more obviously. Reflection pulse peak has an upward trend, rises to 2.16 finally. On the contrary, when the pulse width is equal to $0.5 \mathrm{~ms}$ the input pulse peak is $42.93 \mathrm{~ms}$, with pulse width gradually increases to $2 \mathrm{~ms}$, the magnitude of the input pulse peak falls significantly to $8.9 \mathrm{~ms}$.

According to these data, we get a conclusion: when the magnitude of pulse width of impact hammer is a high value, the magnitude of input pulse peak is a small value, the magnitude of reflection pulse peak is high value; when the magnitude of pulse width of impact hammer is a small value, the magnitude of input pulse peak is a high value, the magnitude of reflection pulse peak is small value.

This phenomenon due to that the impact pulse width is a high value means the frequency of the impact force is low, if it has a big difference between frequency of impact force and pile, the particle displacement at top of the pile will be small, so the peak of input pulse is small. In addition, in the process of propagation, if the frequency of the impact force is small, the energy of stress wave generated by the force will have a smaller loss. Therefore, the reflection will be more obvious.

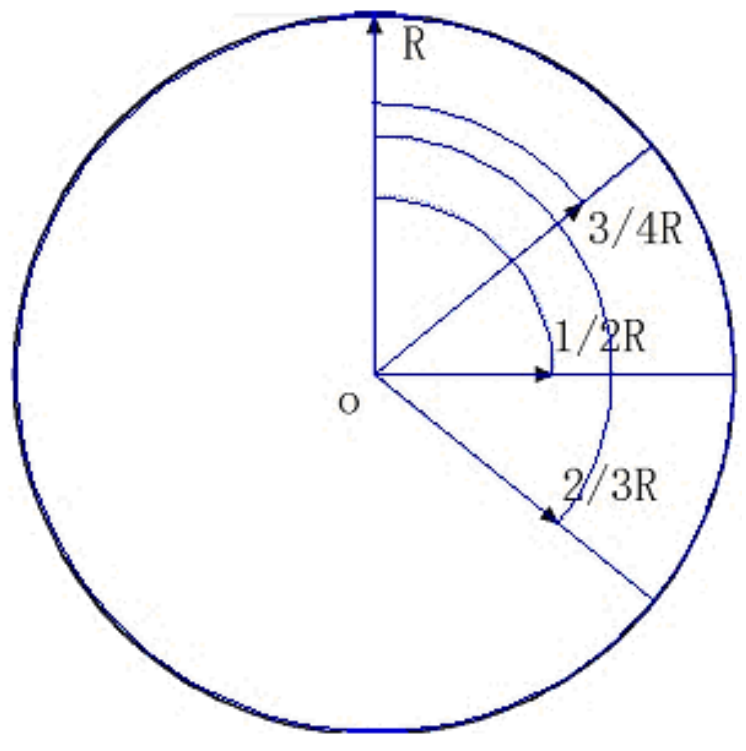

Fig. (6). Chematic diagram of receiving point on pile top.

\section{INFLUENCE OF REFLECTION PULSE DUE TO RE- CEIVING POINT}

As shown in Fig. (6), different receiving points on the surface of the pile top were set respectively at center, 3/4R, $2 / 3 \mathrm{R}$ and $1 / 2 \mathrm{R}$ from the center to get different velocity versus time curves with testing simulation. And the results are presented in Fig. (7).

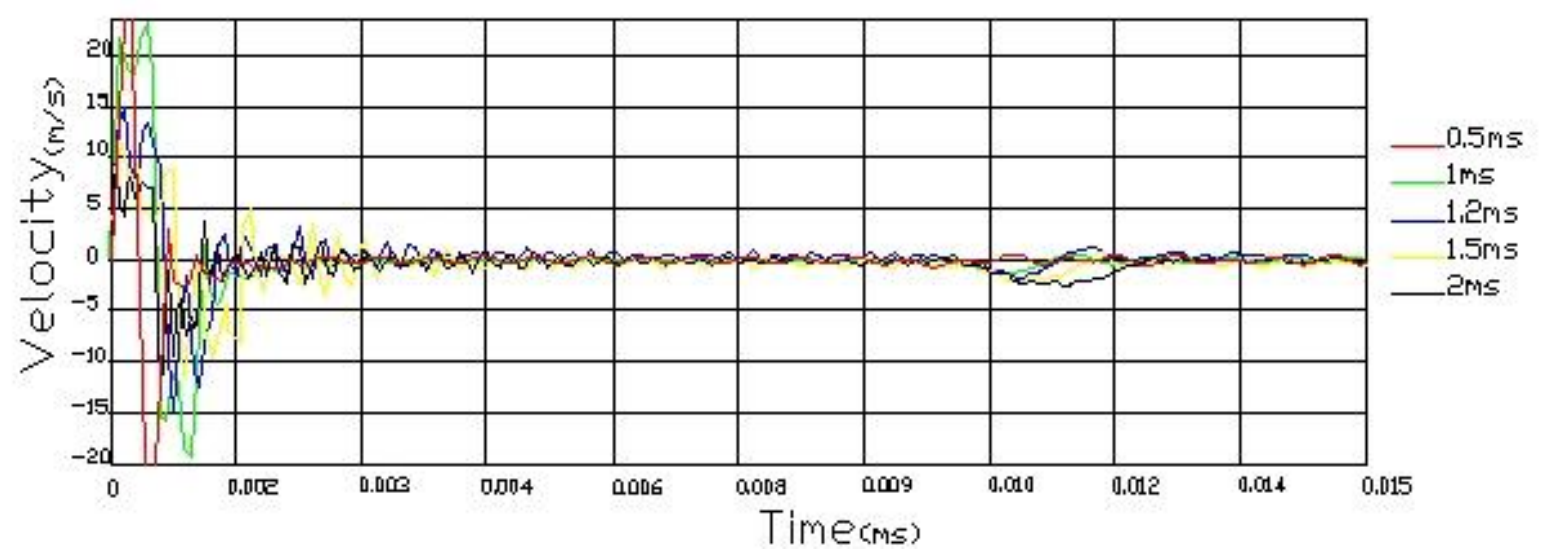

Fig. (5). Velocity vs. time curve for different pulse width.

Table 2. Waveform parameters in different pulse width.

\begin{tabular}{|c|c|c|c|c|c|}
\hline Pulse Width (ms) & $\begin{array}{c}\text { Input Pulse Peak } \\
(\mathrm{m} / \mathrm{s})\end{array}$ & $\begin{array}{l}\text { Reflection Pulse Peak } \\
\qquad(\mathbf{m} / \mathbf{s})\end{array}$ & $\begin{array}{l}\text { Rise Time of Reflec- } \\
\text { tion Pulse (ms) }\end{array}$ & $\Delta t(m s)$ & $\begin{array}{c}\text { Ratio of Input Pulse } \\
\text { Peak to Reflection } \\
\text { Pulse Peak }\end{array}$ \\
\hline 1 & 23.2 & 1.19 & 10.21 & 9.71 & 19.49 \\
\hline 1.2 & 14.78 & 1.72 & 10.52 & 9.92 & 8.59 \\
\hline 2 & 8.9 & 2.16 & 11.03 & 10.03 & 4.12 \\
\hline
\end{tabular}


From Fig. (7) we know that the initial speed of the input pulse is $0 \mathrm{~m} / \mathrm{s}$ for $3 / 4 \mathrm{R}$ and $2 / 3 \mathrm{R}$, this value for $1 / 2 \mathrm{R}$ is $0.75 \mathrm{~m} / \mathrm{s}$ and $1 \mathrm{~m} / \mathrm{s}$ for $1 / 3 \mathrm{R}$. So we can get that: When the distance between receiving point and impact point is less than $1 / 2 \mathrm{R}$, the pulse delay will occur, what's more, the distance from receiving point closer to the center of pile, this phenomenon is more obvious. This phenomenon may result in time error that may cause misjudgment for the location of the defect. If the defect close to the top of pile, with time error, it is hard to determine the location accurately.

Why is there such a phenomenon, as well known, there are three kinds of elastic wave in solids a compressional wave $\mathrm{P}$, a transverse wave $\mathrm{S}$ and a Rayleigh wave R. Since the P's velocity $>$ S's $>$ R's, then we can see P first to arrive at the receiving point. However, the vertical motion of particle caused by $\mathrm{P}$ is small, and it attenuates quickly. $\mathrm{P}$ occupies a small proportion of the impact energy; the majority of the proportion is controlled by R. So, the main influences of velocity of particles which distance from the impact point are dominated by $\mathrm{R}$ and $\mathrm{S}$. Thus, if the receiving point close to the impact point, the phenomenon of input pulse delay will come out.

According to the above analyzed, the receiving point is set at $2 / 3 \mathrm{R}$ to $3 / 4 \mathrm{R}$ is appropriate for concrete pile. However, for reinforced concrete pile, the point which is set around $3 / 4 \mathrm{R}$ is easy to be interfered by the steel vibration. So the best location is at $2 / 3 R$.

\section{ISOCHRONOUS REFLECTION}

For end bearing pile, pile load mainly borne by the pile tip resistance, for friction pile, pile load mainly borne by the pile side resistance. The supporting soil layer of the former basically is requested to have a big bearing capacity eigenvalue, the modulus of this layer and modulus ratio of this layer to the upper layer will be higher than the latter.

According to the stress wave propagation theory, speed of stress wave propagation in the medium is only related to the elastic modulus and density of medium. On the theory, stress wave multiple reflection in the same medium interface should be isochronous. In this part, we will try to prove this theory which can be used to judge the defect of pile. Fig. (8) shows two velocity versus time curves achieved from numerical assessment for end bearing pile and friction pile. Table $\mathbf{3}$ records the specific value of related data.

In Fig. (8), we can see both of the curves' input pulse peaks are about $10 \mathrm{~m} / \mathrm{s}$. For friction pile the phase of two reflection pulses are the same, on the contrary, for end bearing pile the phase of the adjacent reflection pulses are opponent. $\Delta t_{1}$ (time difference from the peak time of input pulse and the peak time of reflection pulse) are similar to keep around at $10 \mathrm{~ms}$. Furthermore, $\Delta \mathrm{t}_{2}$ (time difference from the peak time of first reflection and the peak time of second reflection pulse) is equal to $\Delta \mathrm{t}_{1}$. It proves that both end bearing pile and friction pile have the characters of isochronous reflection.

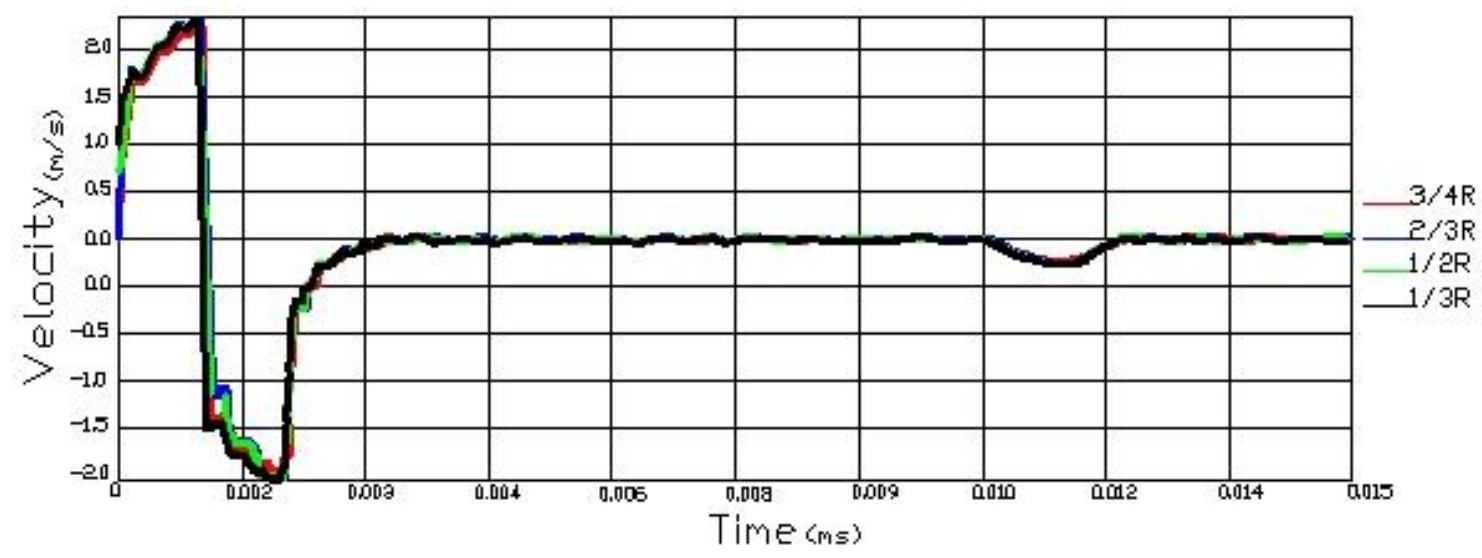

Fig. (7). Velocity vs. time curve in different R.

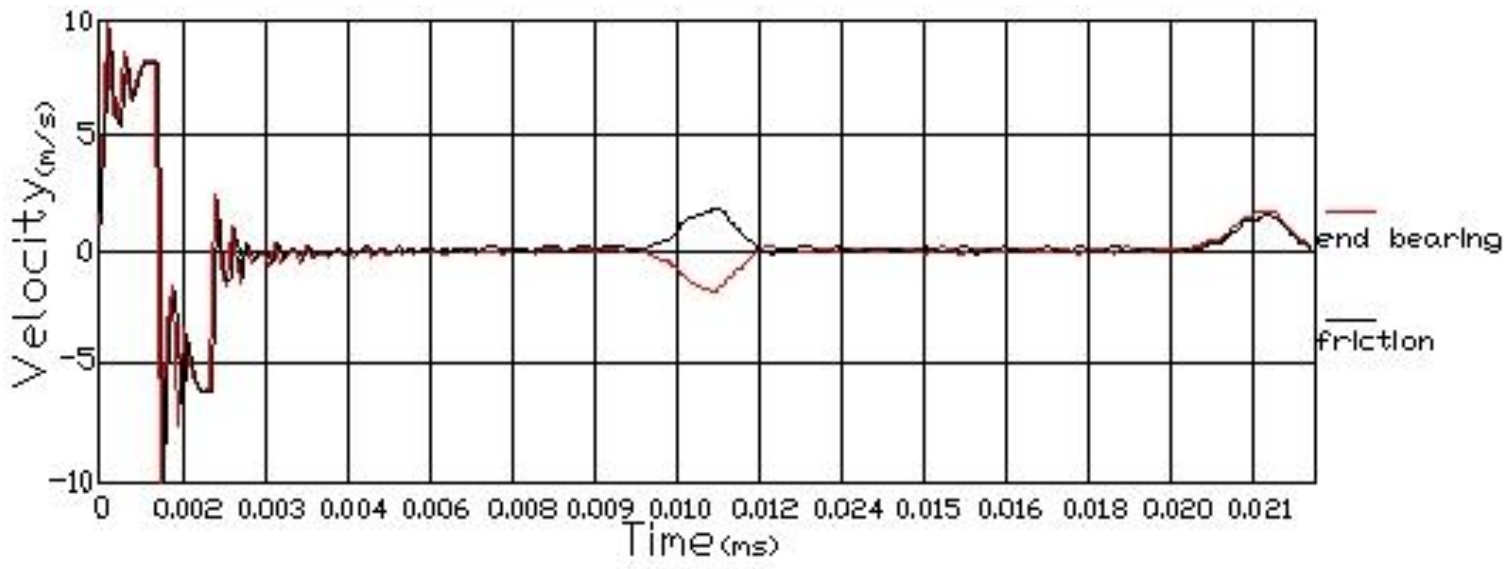

Fig. (8). Velocity vs. time curve for end bearing pile and friction pile. 
Table 3. Reflection parameters of integral end bearing pile and friction pile.

\begin{tabular}{|c|c|c|c|c|c|}
\hline & $\begin{array}{c}\text { Input Pulse Peak } \\
(\mathbf{m} / \mathbf{s})\end{array}$ & $\begin{array}{c}\text { First Reflection Pulse } \\
\text { Peak (m/s) }\end{array}$ & $\begin{array}{c}\text { Second Reflection } \\
\text { Pulse Peak (m/s) }\end{array}$ & 1.73 & $\begin{array}{c}\text { Ratio of Input Pulse } \\
\text { Peak to Reflection } \\
\text { Pulse Peak }\end{array}$ \\
\hline \hline Integral end bearing pile & 10 & 1.83 & 1.68 & 9.91 & 10.02 \\
\hline Friction pile & 9.9 & 1.93 & $5.46,5.78$ & $5.12,5.89$ \\
\hline
\end{tabular}

As shown in Fig.8, we get conclusion that isochronous can also be used as the basis for judging defects of pile. When a real pile integrity test carry out in a field, if isochronous character is not occurs in the velocity versus time curves, the pile may exists complex defects or several defects.

\section{INFLUENCE OF REFLECTION PULSE DUE TO SOIL MODULUS}

As we all known, deformation modulus of soil of each project is different, so study the effects of soil deformation modulus on the waveform of velocity versus time curve is necessary. Usually engineering geological exploration report provides the compression modulus $\mathrm{E}_{\mathrm{S}}$ of soil which also can be determined by formula (1) and (2).
$E_{S}=\frac{1}{\beta} E$

$\beta=1-\frac{2 v^{2}}{1-v}$

Where: E- elastic (deformation) modulus of soil, v- Passion's ratio.

Fig. (9) shows the velocity versus time curves through simulate testing of friction pile in different kinds of soil. Impact force was also set to $6 \mathrm{~N}$, impulse width was set to $2 \mathrm{~ms}$ and computing time was set to $15 \mathrm{~ms}$. Table 4 records reflection parameters of friction pile in different soil.

As shown in Table 4, when the E soars dramatically to $100 \mathrm{MPa}$ from $1 \mathrm{MPa}$, the input pulse peak increases slightly,

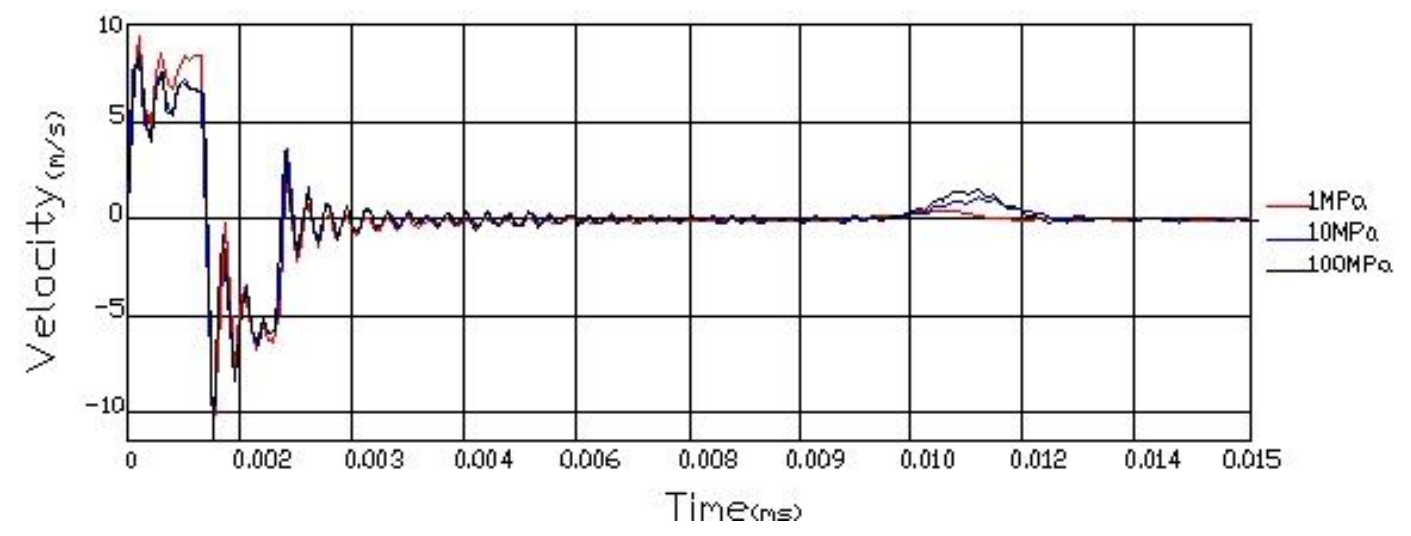

Fig. (9). Velocity vs. time curve for different soil modulus.

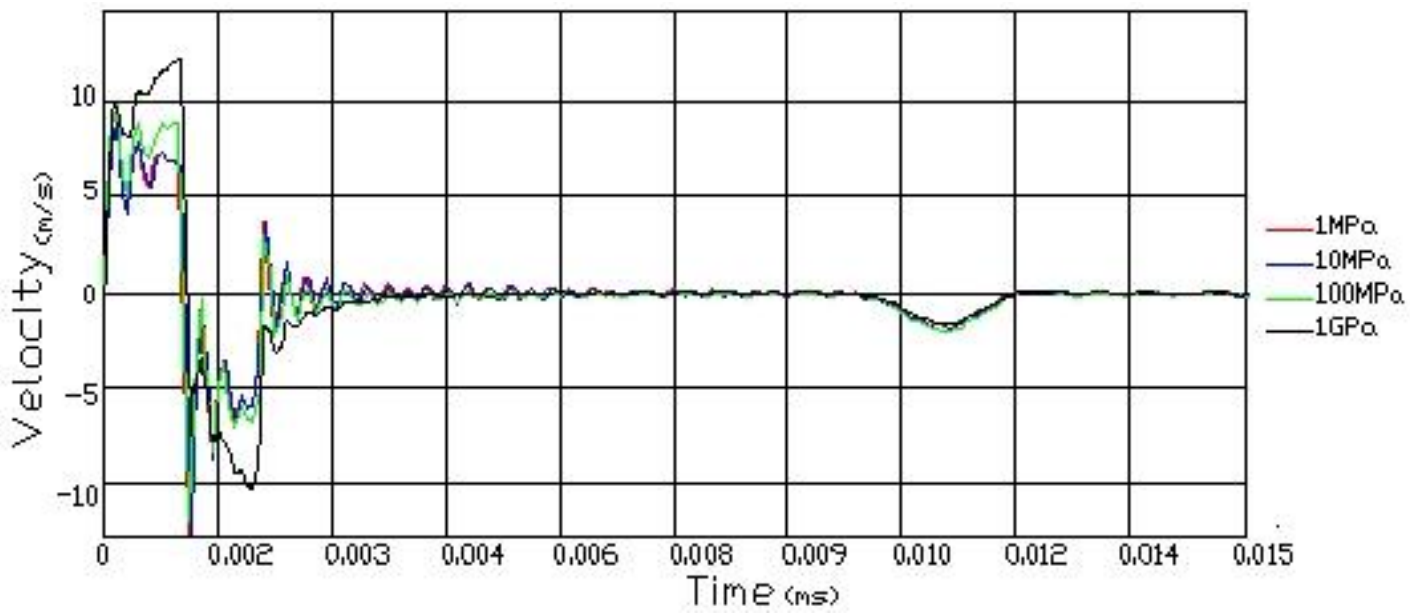

Fig. (10). Velocity vs. time curve for different pressures. 
Table 4. Reflection parameters for friction pile in different soil.

\begin{tabular}{|c|c|c|c|c|}
\hline $\mathbf{E}$ & Input Pulse Peak $(\mathbf{m} / \mathbf{s})$ & Reflection Pulse Peak $(\mathbf{m} / \mathbf{s})$ & $\Delta \mathbf{t}(\mathbf{m s})$ & Ratio of Input Pulse Peak to Reflection Pulse Peak \\
\hline \hline $1 \mathrm{MPa}$ & 9.46 & 0.49 & 9.71 & 19.3 \\
\hline $10 \mathrm{MPa}$ & 8.82 & 1.16 & 10.12 & 7.6 \\
\hline $100 \mathrm{MPa}$ & 8.71 & 1.65 & 10.04 & 5.27 \\
\hline
\end{tabular}

Table 5. Reflection parameters of end bearing pile in different soil.

\begin{tabular}{|c|c|c|c|c|}
\hline E & Input Pulse Peak (m/s) & Reflection Pulse Peak (m/s) & $\Delta \mathbf{t}(\mathbf{m s})$ & $\begin{array}{c}\text { Ratio of Input Pulse Peak to } \\
\text { Reflection Pulse Peak }\end{array}$ \\
\hline \hline $1 \mathrm{MPa}$ & 8.82 & 1.87 & 9.91 & 4.71 \\
\hline $10 \mathrm{MPa}$ & 8.84 & 1.89 & 10.12 & 4.68 \\
\hline $100 \mathrm{MPa}$ & 9.12 & 1.88 & 10.01 & 4.85 \\
\hline $1 \mathrm{GPa}$ & 13.39 & 1.80 & 9.94 & 7.43 \\
\hline
\end{tabular}

the input pulse peak tends to be stable at $8.8 \mathrm{~m} / \mathrm{s}$ around. On the contrary, reflection pulse peak has an obviously variation, the value increases with the magnification of $\mathrm{E}$, and the ratio of input pulse peak to reflection pulse peak decline to 5.27 from 19.3.

Fig. (10) shows the velocity versus time curves through simulate testing of end bearing pile in different kinds of soil. Impact force was also set to $6 \mathrm{~N}$, impulse width was set to $2 \mathrm{~ms}$ and computing time was set to $15 \mathrm{~ms}$. Table 5 records reflection parameters of end bearing pile in different soil.

As shown in Table 5, when the E soars dramatically from $1 \mathrm{MPa}$ to $10 \mathrm{MPa}$, the input pulse peak almost has no change, after that, the input pulse peak increases when the value of $E$ beyond $10 \mathrm{MPa}$. On the contrary, reflection pulse peak has no obvious variation. The ratio of input pulse peak to reflection pulse peak soars from 19.3 to 7.43 .

According to the above analysis, for friction pile, with the soil modulus increase input pulse basically remain unchanged, the reflection peak value increases, ratio of input pulse peak to reflection pulse peak declines, for end bearing pile, with the soil modulus reflection peak increase basically remain unchanged, input pulse value increases, ratio of input pulse peak to reflection pulse peak rises.

\section{CONCLUSION}

From the numerical tests and above analysis, we can get the following regularities as a reference:

(1) In this assessment, $100 \mathrm{~mm}$ is found as an appropriate mesh size that make the reflection from pile toe looks more obvious.

(2) Using an impact hammer with a high pulse width, the reflection pulse from pile toe will be more obvious.

(3) As a result of analysis for the position of the pile top signal receiver influence on waveform, distance from center for $2 / 3$ to $3 / 4 \mathrm{R}$ is more appropriate for concrete pile, and $2 / 3 \mathrm{R}$ is the best for reinforced concrete pile.
(4) Isochronous of reflection are existed for both end bearing pile and friction pile, that can be an important basis to determine the defect position in the situation that complex defect exists in pile.

(5) For integral friction pile, with the soil modulus increase gradually, the input pulse peak basically remain unchanged, and reflection pulse peak increases gradually. For integral end bearing pile, with the soil modulus increase gradually, the input pulse peak also increases, but reflection pulse peak basically remain unchanged.

\section{REFERENCES}

[1] F. Chen and R.J. Wang, "Dimension effect on low strain integrity testing of piles", Chinese Journal of Geotechnical Engineering, vol. 20, pp. 92-96, May 1998.

[2] F. Chen and W. Z. Luo, "Effect on low strain integrity testing of prestressed pipe piles", Chinese Journal of Geotechnical Engineering, vol. 26, pp. 353-356, Mar. 2004.

[3] Y. K. Chow, K. K. Phoon, W. F. Chow and K.Y. Wong, "Low strain integrity testing of piles: three-dimensional effects", Journal of Geotechnical and Geoenvironmental Engineering, vol. 129, pp.10571062, Nov. 2003.

[4] D. Z. Huang and L. Z. Chen, "3D finite element analysis of reflected waves in concrete pipe pile with defects", Rock and Soil Mechanics, vol. 26, pp. 804-808, May 2005.

[5] Y. Q. Chen, Z. G. Ren and D. J. Liu, "Simulation and calculation of transient longitudinal vibration of non-integrate piles", Journal of Hefei University of Technology (Natural Science), vol. 27, pp.12101214, Oct. 2004.

[6] Z. B. Ke, D. J. Liu and X. T. Liao. "Numerical calculation of torsional vibration of intact piles", Journal of Hefei University of Technology (Natural Science), vol. 28, pp.1446-1448, Nov. 2005.

[7] L.L. Long, D. J. Liu, Z. T. Lu and F. Xu, "Simulation and calculation of transient lateral vibration of integrate piles based on Timoshenko beam", Journal of Hefei University of Technology (Natural Science), vol. 34, pp. 403-407, Mar. 2011.

[8] Z. T. LU, Z. L. Wang, D. J. Liu and X. F. Yang, "Analysis of 3-D effects in low strain testing of pipe pile", Journal of Tongji University (Natural Science), vol. 40, pp.1603-1653, Nov. 2012.

[9] W. Y. Zhang, X. F. Wang, Y. Gan, P. Chen and Y.Y. Xin "Analysis of factors to affect the hitting effect in piles' dynamic test", Sichuan Building Science, vol. 37, pp.140-145, Apr. 2011.

[10] H. Chen, J. D. Wang, "The low strain reflected waveform curve analyses of defect pile commonly occur in the engineering", Railway Engineering, vol.6, pp. 44-46, June 2013. 
[11] X. M. Ding and H. M. Tan, "Study on the velocity responses of large-diameter pipe pile with variable wave impedance in low strain integrity testing", Journal of Sichuan University(Engineering Science Edition), vol. 43, pp.18-25, Mar. 2011.

[12] X. M. Ding and H. L. Liu, "Time-domain analytical solution of the vibration response of a large-diameter pipe pile subjected to transient concentrated load", Chinese Journal of Geotechnical Engineering, vol. 35, pp.1010-1017, June 2013.

[13] Z. G. Wang, L. Chen and Z. C. Xiao, "Reflection waveform analysis of necking pile under low strain", The Electronic Journal of Geotechnical Engineering, vol.18, pp. 5599-5609, 2013.

[14] X. J. Shi, Q. X. Yue and J. Li, "Influence factor analysis of foundation model in shaking table test considering soil-structure dynamic interaction", Journal of Architecture and Civil Engineering, vol. 24, pp. 50 -53, Apr. 2007.

[15] D. L. Qian, Y. Y. Zhao and D. P. Wang, "Experimental study on the dynamic interaction of squeezed branch pile - soil - structure system by shaking table test", Journal of Shanghai Jiaotong University, vol. 39, pp.1856-1861, Nov. 2005.

[16] J. P. Jiang, M. W. Wang and G. Y. Gao, "Contrastive study on influence of difference of pile end rock-soil layer on super-long pile", Chinese Journal of Rock Mechanics and Engineering, vol.23, pp. 3190-3195, Sep. 2004.

[17] D. Brown "Effect of construction on axial capacity of drilled foundations in piedmont soils", Journal of Geotechnical and Geoenvironment Engineering, vol.128, pp. 967-973, Dec. 2002.

(C) Wang et al.; Licensee Bentham Open.

This is an open access article licensed under the terms of the Creative Commons Attribution Non-Commercial License (http://creativecommons.org/licenses/ by-nc/3.0/) which permits unrestricted, non-commercial use, distribution and reproduction in any medium, provided the work is properly cited. 